OPEN ACCESS

Edited by:

Mingli Xu,

University of South Carolina

United States

Reviewed by:

Yun Ju Kim,

Institute for Basic Science (IBS),

South Korea

$\operatorname{Lin} X u$,

Center for Excellence in Molecular

Plant Sciences, Chinese Academy

of Sciences (CAS), China

*Correspondence:

Binglian Zheng

zhengbl@fudan.edu.cn

Specialty section:

This article was submitted to

Plant Development and EvoDevo,

a section of the journal

Frontiers in Plant Science

Received: 01 December 2021

Accepted: 31 December 2021

Published: 03 February 2022

Citation:

Jiang $T$ and Zheng B (2022) Epigenetic Regulation of Megaspore

Mother Cell Formation.

Front. Plant Sci. 12:826871.

doi: 10.3389/fpls.2021.826871

\section{Epigenetic Regulation of Megaspore Mother Cell Formation}

\author{
Ting Jiang and Binglian Zheng*
}

State Key Laboratory of Genetic Engineering, Ministry of Education Key Laboratory of Biodiversity Sciences and Ecological Engineering, Collaborative Innovation Center of Genetics and Development, School of Life Sciences, Fudan University,

Shanghai, China

In flowering plants, the female gametophyte (FG) initiates from the formation of the megaspore mother cell (MMC). Among a pool of the somatic cells in the ovule primordium, only one hypodermal cell undergoes a transition of cell fate to become the MMC. Subsequently, the MMC undergoes a series of meiosis and mitosis to form the mature FG harboring seven cells with eight nuclei. Although SPL/NZZ, the core transcription factor for MMC formation, was identified several decades ago, which and why only one somatic cell is chosen as the MMC have long remained mysterious. A growing body of evidence reveal that MMC formation is associated with epigenetic regulation at multiple layers, including dynamic distribution of histone variants and histone modifications, small RNAs, and DNA methylation. In this review, we summarize the progress of epigenetic regulation in the MMC formation, emphasizing the roles of chromosome condensation, histone variants, histone methylation, small RNAs, and DNA methylation.

\footnotetext{
Keywords: MMC, epigenetic regulation, small RNA, DNA methylation, ovule development epigenetic regulation in MMC
}

\section{INTRODUCTION}

Different from that in animals, the germline cells are not specialized during embryo development in plants. Instead, when plants grow from vegetative growth to reproductive growth, several specific somatic cells undergo cell fate transition to become the germline cells. In flowering plants, the male and female gametophytes (FGs) develop within the anther and the ovule, respectively. In most angiosperms and gymnosperms, only one somatic cell in the nucellus region of the ovule changes its cell identity and later becomes the megaspore mother cell (MMC). MMC undergoes two meiotic divisions to give rise to four megaspores. Then, only one megaspore near the chalaza becomes the functional megaspore (FM), while the other three cells undergo programmed cell death. Subsequently, the FM undergoes three mitotic nuclear divisions, finally resulting in the formation of a mature FG, so called embryo sac (Grossniklaus and Schneitz, 1998). As the first step of FG development, cell fate transition of MMC is of great importance.

In Arabidopsis, the pre-meiosis ovule can be divided into three parts along a proximal-distal axis, including nucellus, chalaza, and funiculus (Schneitz et al., 1997). The cells in the nucellus region can be further divided into two layers, the epidermal layer (L1) and the subepidermal layer (L2). In general, the archespore that arises from the most distal cell in L2 changes its cell fate to develop into MMC. Subsequently, the MMC becomes recognizable as a single, large, and elongated subepidermal cell, which is centrally positioned within the nucellus and displays a prominent 
nucleus and nucleolus (Schneitz et al., 1997; Hernandez-Lagana et al., 2021; Figure 1). However, the mechanism of MMC formation remains unclear, especially, which, why, and how only one somatic cell is allowed to become MMC? In general, MMC formation is thought to be controlled by two steps: first, restricting only one cell differentiation to MMC, and second, preventing self-renewal of the designated MMC before meiosis. Here, we review major advances in the cell fate control of MMC, emphasizing the roles of epigenetic regulations, including the change of chromosome condensation status, distribution of histone variants and histone modifications, small RNA biogenesis, and DNA methylation.

\section{KEY DEVELOPMENTAL REGULATORS OF MEGASPORE MOTHER CELL FORMATION}

SPOROCYTELESS/NOZZLE (SPL/NZZ), a MADS-box transcriptional factor, is the first gene which was found to play a pioneer role in MMC formation, as the $s p l / n z z$ mutants have smaller nucellus and the archespore completely fails to undergo differentiation resulting in the complete absence of the MMC (Schiefthaler et al., 1999; Yang et al., 1999; Balasubramanian and Schneitz, 2000). In contrast, a recent study shows that ectopic expression of SPL/NZZ caused additional enlarged MMC-like cells in the early ovules (Mendes et al., 2020). Of note, as a pioneer transcription factor in germline formation, SPL/NZZ is also required for male gametophyte development, as microsporocyte formation was blocked in the SPL/NZZ mutants (Schiefthaler et al., 1999; Yang et al., 1999). The homologs of SPL/NZZ in tomato and rice are also essential for both male and FG development (Rojas-Gracia et al., 2017; Ren et al., 2018). SPL/NZZ uses its EAR motif to recruit co-repressor TOPLESS, to regulate sporocyte formation (Chen et al., 2014; Wei et al., 2015). Moreover, WUSCHEL (WUS), a key regulator for stem cell fate in plants, acts in concert with SPL/NZZ to contribute MMC formation (Lieber et al., 2011). Based on the observations that SPL/NZZ is mainly expressed at the tip of the ovule primordium (Mendes et al., 2020; Zhao et al., 2020), and WUS preferentially accumulates in the nucellar cells surrounding the MMC (Zhao et al., 2017; He et al., 2019; Mendes et al., 2020), it is thought that the roles of both SPL/NZZ and WUS in regulating MMC formation are non-cell-autonomous (Figure 1).

Once MMC specification is determined, the MMC undergoes meiosis to produce the four megaspores and only one of megaspores called FM develops into the mature FG via several rounds of mitoses (Grossniklaus and Schneitz, 1998). However, why the MMC is able to switch mitotic division to meiotic division? Cyclin-dependent kinase (CDK) inhibitor KIPRELATED PROTEIN (KRP) family inhibit CDKA;1 to ensure the entry of MMC into meiosis rather than mitosis (Zhao et al., 2017; Figure 1). By analyzing MMC formation in the triple mutant of KRP, Zhao et al. (2017), shows that KRPs are essential for the restriction of the plant germline harboring only one MMC per ovule by inhibiting CDKA;1. Furthermore, CDKA;1 targets RETINOBLASTOMA-RELATED 1 (RBR1), a Retinoblastoma
(Rb) homolog in Arabidopsis (Ebel et al., 2004), to inhibit the designated meiocytes entering mitosis (Zhao et al., 2017). As a result, the meiocytes of the rbr1 mutants undergo several mitotic divisions, resulting in the formation of supernumerary meiocytes that give rise to multiple MMCs per ovule (Zhao et al., 2017). Intriguingly, the expression of WUS expands from the surrounding somatic cells to the MMC in both $k r p$ and $r b r 1$ mutants (Zhao et al., 2017). Moreover, loss-of-function of WUS significantly restored the phenotype of multiple MMCs in the rbr1 mutants (Zhao et al., 2017). However, ectopic expression of WUS failed to induce the entry of MMC into mitotic divisions, suggesting that RBR1 not WUS is a central hub to determine the switch of MMC differentiation (Zhao et al., 2017). In addition, RBR1 represses cell cycle regulator E2F transcription factors to regulate the cell fate of MMC, as the $e 2 f$ mutant harbors two to three MMCs per ovule primordium (Yao et al., 2018). Altogether, these findings indicate that not only MMC specification but also MMC differentiation are tightly regulated (Figure 1).

\section{DE-CONDENSED CHROMATIN AND DECREASED HETEROCHROMATIN IN THE MEGASPORE MOTHER CELL}

Once a specific somatic cell is chosen to develop into the MMC, both the cell itself, the nucleus, and even the nucleolar of the MMC increase significantly in size (Schneitz et al., 1997), which mark the MMC distinguishable clearly from the surrounding somatic cells. Chromatin condensation and heterochromatin formation are usually correlated to the nucleus size (van Zanten et al., 2011; Wang et al., 2013). Using non-denaturing wholemount DNA staining and confocal imaging, She et al. (2013) showed the MMC exhibits a $60 \%$ reduction in heterochromatin content and a decreased number of chromocenters, indicating that a quick establishment of a MMC-specific chromatin state.

Histone H1, a linker histone, establishes the compaction state of an array of nucleosomes to influence the status of chromatin condensation (Osipova et al., 1980). In Arabidopsis, $\mathrm{H} 1$ is encoded by three genes, H1.1, H1.2, and H1.3 (Ascenzi and Gantt, 1997). H1.1 and H1.2 are significantly down-regulated in the MMC, and $H 1.3$ is barely detected in the ovule primordia (She et al., 2013). Moreover, H1.1 and H1.2 are de novo incorporated into the chromatin for condensation as meiosis occurs (She et al., 2013), suggesting that the decrease of $\mathrm{H} 1$ might be the consequence after a somatic cell is specialized into the MMC (Figure 2).

Consistent with the role of $\mathrm{H} 1$ in chromosome condensation, loss-of-function of $\mathrm{H} 1$ causes a global decrease of heterochromatin formation and transposon silencing (Zemach et al., 2013; He et al., 2019). In plants, heterochromatin formation is usually associated with decreased active histone modifications, for example, $\mathrm{H} 3 \mathrm{~K} 4 \mathrm{me} 3$, and increased inactive histone modifications, such as $\mathrm{H} 3 \mathrm{~K} 27 \mathrm{me} 3$ and $\mathrm{H} 3 \mathrm{~K} 9 \mathrm{me} 2$ (Bender, 2004). Immunofluorescence assays show, in contrast to those in the surrounding cells, $\mathrm{H} 3 \mathrm{~K} 4 \mathrm{me} 3$ is enriched to 2.7 -fold in the MMC while H3K27me1, H3K9me2, and H3K27me3 reduced in the MMC (She et al., 2013), indicating 


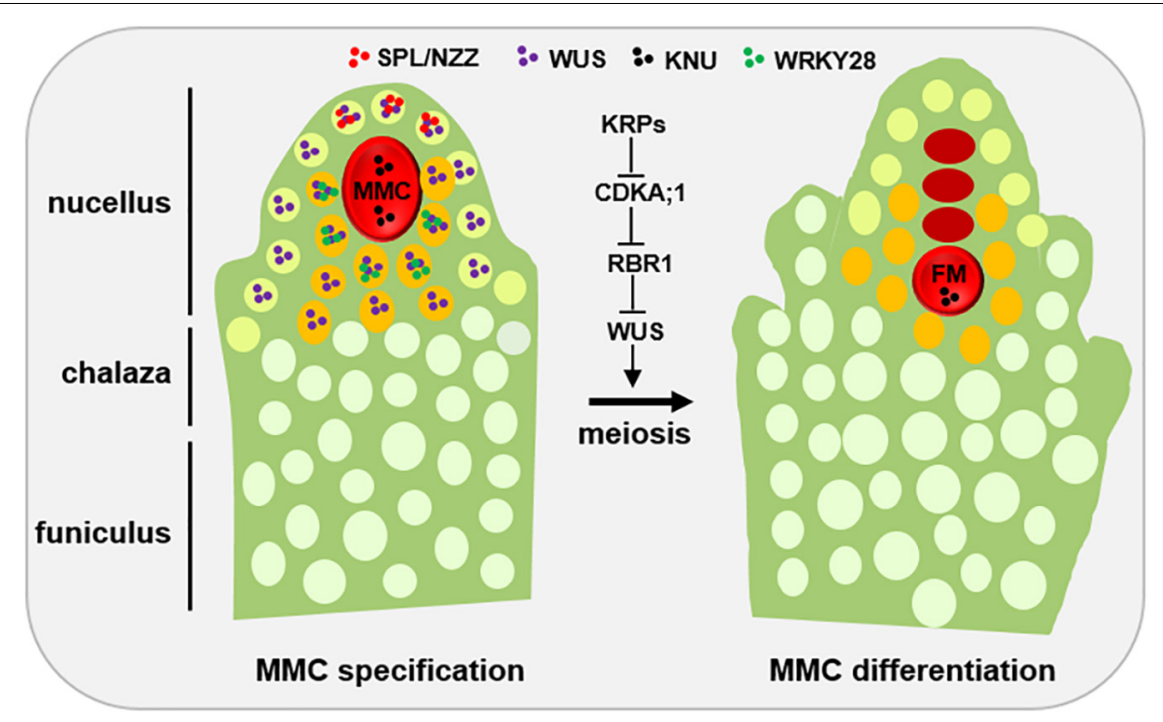

FIGURE 1 | Developmental schematic of MMC formation. In the early ovule (left), several pioneer transcription factors, mainly SPL/NZZ and WUS, play an important role in promoting MMC formation. The spatial distribution of SPL, WUS and WRKY28 away from the centered position of the nucellus region is the prerequisite of MMC specification and MMC differentiation, respectively. KNU, a widely used MMC marker. Once the MMC specification is finished, the KRP-CDKA;1-RBR1 pathway plays a key role to ensure the MMC into meiotic rather than mitotic competency by inhibiting the expansion of WUS into the MMC. L1 cell, light green; $\mathrm{L} 2$ cell, orange; MMC, megaspore mother cell, red; FM, functional megaspore, red. Other distal somatic cells are indicated in light white.

a permissive chromatin environment of the MMC (Figure 2). Correspondingly, SET DOMAIN GROUP 2 (SDG2), a writer for H3K4me3 (Berr et al., 2010; Guo et al., 2010), and LHP1, a key regulator for $\mathrm{H} 3 \mathrm{~K} 27 \mathrm{me} 3$, are highly and barely expressed in the MMC, respectively (She et al., 2013). These observations indicate that with the increase of both cell size and nuclear even nucleolar size, histone modifications are actively regulated to establish a unique permission chromatin environment for the MMC.

\section{HISTONE VARIANTS ARE ACTIVELY EXCHANGED TO CONCERT THE MEGASPORE MOTHER CELL CHROMATIN STATUS}

Accompanied with chromatin condensation, histone variants often confer specific structure and functional chromatin features due to their substitutable capacity for the core canonical histone in nucleosomes in eukaryotes. Among multiple histone variants, histone $\mathrm{H} 3$ is encoded by HISTONE THREE RELATED (HTR) gene family containing 15 members in Arabidopsis (Okada et al., 2005). HTR12, a centromere-specific H3 variant CENH3 (Talbert et al., 2002), was ubiquitously expressed in the MMC (Ravi et al., 2011; She et al., 2013). By contrast, HTR8 and HTR5, two $\mathrm{H} 3.3$ variants that are usually associated with transcriptional competence (Ingouff et al., 2010), are specifically expressed in the MMC (She et al., 2013). HTR13, a H3.1 variant that is usually related inactive transcription activity (Jacob et al., 2014), can be gradually evicted in multiple L2 cells of the nucellus during early ovule development, but this eviction was only limited to the MMC once the identity of the MMC is designated (Hernandez-Lagana and Autran, 2020; Figure 2). The eviction of $\mathrm{H} 3.1$ in the MMC indicates that H3.1 can act as a marker to distinguish cell identity, which also happens in the root quiescent center (Otero et al., 2016). The phenomenon of multiple early L2 cells with H3.1 eviction suggests that not only one L2 cell has acquired the potential to turn into the germline cell, but finally only one can switch to the MMC by an unknown mechanism (Hernandez-Lagana and Autran, 2020).

In contrast to $\mathrm{H} 3$ variants, HTA11, a H2A.Z variant, is evicted from the early MMC but reincorporated later (She et al., 2013). Moreover, WRKY28, a transcription factor labeling the L2 cells, is activated by cytochrome P450 gene KLU through the chromatin remodeling complex SWR1-mediated H2A.Z deposition (Qin et al., 2014; Zhao et al., 2018). Therefore, although the mechanism by which specific chromatin hallmarks are differentially regulated in the MMC is unknown, the highly dynamic exchange among H1, H3.1, H3.3, H2A.Z, and CENH3 is consistent with a global pattern of chromatin de-condensation in the MMC, indicating that a specific chromatin reprogramming during MMC specification and differentiation (Figure 2).

\section{SMALL RNA NEGATIVELY REGULATES MEGASPORE MOTHER CELL FORMATION}

Based on the modes of biogenesis and action, small RNAs in plants are usually divided into three groups: microRNA (miRNA), small interfering RNA (siRNA), and trans-acting siRNA (tasiRNA) (Borges and Martienssen, 2015). In general, 


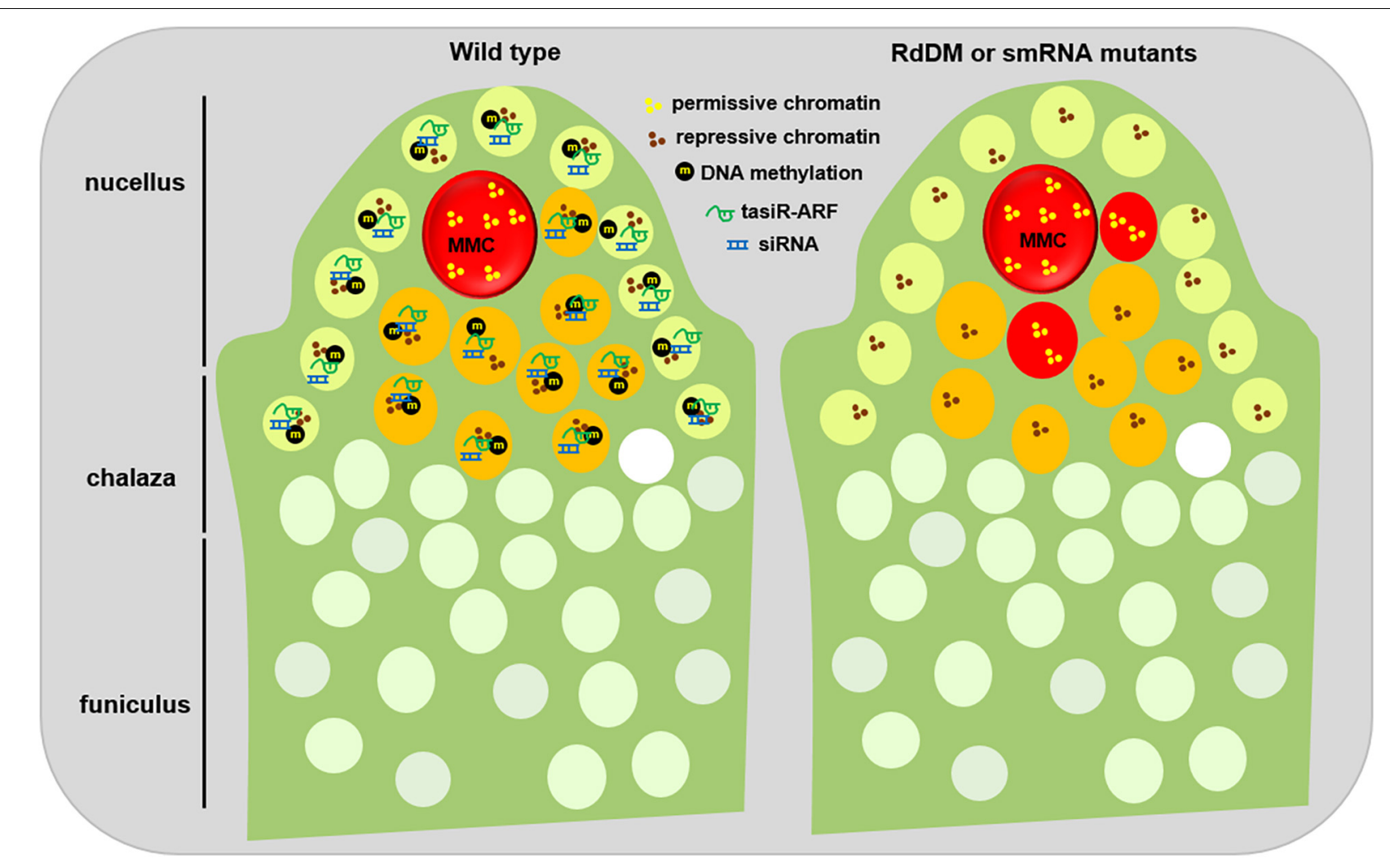

FIGURE 2 | Epigenetic regulation of MMC formation. During early ovule development of the wild type plants (left), small RNA, mainly tasiRNA and siRNA, are widely produced. On one hand, tasiRNAs impede the surrounding somatic cells to activate their potential germline identity by inhibiting ARF3 to the nucellus region; on the other hand, siRNAs reinforce the repressive chromatin status of the surrounding cells by guarding DNA methylation and/or histone modification. Meanwhile, several inactive histone modifications, such as $\mathrm{H} 1, \mathrm{H} 3 \mathrm{~K} 9 \mathrm{me} 2$, and $\mathrm{H} 3 \mathrm{~K} 27$ me3, facilitate the maintenance of repressive chromatin status in the surrounding cells. In contrast, the MMC shows a higher level of active histone modifications, for example, H3K4me3, thus keeping a permissive chromatin state. When the activities of small RNAs or DNA methylation are disrupted (right), the surrounding somatic cells adjacent to the MMC obtain a permissive chromatin state, and switch to the germline cell identity. This epigenetic dimorphism between the surrounding somatic cells and the MMC might ensure the establishment of a permission chromatin status in the MMC. L1 cell, light green; L2 cell, orange; MMC, megaspore mother cell, red.

MIRNA genes are transcribed into hairpin structured-precursor RNAs followed by Dicer-like 1 (DCL1)-mediated twice cleavages to produce 21-24 nt miRNAs, then miRNAs are mainly loaded onto Argonaute 1 (AGO1) for target gene inhibition with sequence complementarity (Rogers and Chen, 2013). siRNAs are mainly originated from heterochromatic regions, including transposable elements (TE) and DNA repeats. The heterochromatic regions are transcribed into double-stranded RNA precursors by Pol II-RDR6 (RNA-Dependent RNA Polymerase 6) or Pol IV-RDR2. Then, these precursors are cleaved by DCL3 to produce 21-24 nt siRNAs, which are mainly loaded onto AGO4 with the guidance of Pol V-transcribed scaffold RNAs. Lastly, the AGO4-siRNA complex recruits de novo DNA methyltransferase DRM2 to initiate DNA methylation for heterochromatic silencing (Matzke and Mosher, 2014). The siRNA pathway is called RdDM (RNA-directed DNA methylation). In contrast to miRNA and siRNA, tasiRNA biogenesis is initiated from specific miRNA-mediated target cleavage processes, in which non-coding TAS transcripts are cleaved by AGO1-miR173 or AGO7-miR390, then the cleavage products are copied into double-stranded RNAs by RDR6 with the help of SGS3 (Suppressor of Gene Silencing 3), finally these double-stranded RNAs are diced into 21 or 24 nt tasiRNA by DCL4 (Allen et al., 2005). Similar to miRNA, tasiRNAs are mainly loaded onto AGO1 to inhibit target genes.

By focusing on the function of those genes highly expressed in the FG, AGO9 was first isolated due to additional enlarged MMClike cell formation in the ago 9 mutants (Olmedo-Monfil et al., 2010). Subsequently, further genetic analysis show that AGO4, AGO6, AGO8, other three components of the same subclass of AGO9, are all involved in MMC formation (Hernandez-Lagana et al., 2016). Consistent with the function of AGO9 in the siRNA pathway, Pol IV, RDR2, and DCL3, three key genes responsible for siRNA biogenesis, all exhibited increased incidence of additional MMC-like cells (Olmedo-Monfil et al., 2010). Of note, different ecotypes of Arabidopsis exhibit differences in the numbers of MMC, and this variation is largely correlated to the pattern differences of transcriptional regulation and localization of AGO9 in the MMC among ecotypes (Rodriguez-Leal et al., 2015). These observations demonstrate that the siRNA pathway is required to restrict the differentiation of sub-epidermal cells into the MMC in pre-meiotic ovules. 
Besides those mutants in the siRNA pathway, the $r d r 6$, mir390, ago 7, tas3, mutants that affect tasiRNA biogenesis, also exhibits additional MMC-like cells per ovule (Olmedo-Monfil et al., 2010; $\mathrm{Su}$ et al., 2020). By screening new genes acting with RDR6 together to restrict MMC formation, TEX1, HPR1, and THOC6, several components of the THO/TREX complex, were identified as their corresponding mutants exhibit additional MMC-like cells in some pre-meiosis ovules (Su et al., 2017). The isolation of the tho/trex mutants is not surprising because the THO/TREX complex, similar to RDR6, is required for tasiRNA biogenesis (Jauvion et al., 2010; Yelina et al., 2010). Further evidence shows that tasiRNA inhibits the surrounding L2 cells into the MMC by restricting the expression of Auxin Responsive Factor 3 (ARF3) to the nucellus region (Su et al., 2017, 2020). Ectopic expression of ARF3 with TAS3 binding site mutation in the lateral epidermal cells caused multiple MMC cells per ovule primordium ( $\mathrm{Su}$ et al., 2020), suggesting that the inhibition of ARF3 is prerequisite for the restriction of one MMC per primordium. Moreover, these enlarged MMC-like cells of the tasiRNA mutants showed expression of $K N U$, a marker gene for MMC (Payne et al., 2004), indicating that these additional enlarged MMC-like cells have acquired the identity of MMC (Su et al., 2017). Collectively, these findings uncover the role of two small-RNA pathways in the restriction of MMC specification and differentiation (Figure 2).

\section{DNA METHYLATION NEGATIVELY REGULATES MEGASPORE MOTHER CELL FORMATION}

Since the siRNA pathway is required for MMC formation, and siRNA plays a role in gene silencing via guiding DNA methylation in plants, i.e., RdDM (Matzke and Mosher, 2014). However, little is known about DNA methylation dynamics during reproduction largely due to the technical difficulty of isolating pure and sufficient germ cells for evaluation. By developing two live imaging sensors targeting CG (MBD-Venus) and nonCG (SUVH9-Venus) methylation, respectively, Ingouff et al. (2017) showed that in contrast to the relative steady level of CG methylation during whole MMC formation, $\mathrm{CHH}$ methylation became undetectable in the MMC. The reduced levels of DNA methylation correlate with the de-condensed chromatin status and reduced heterochromatin formation in the MMC.

Besides siRNA biogenesis machinery (Pol IV, RDR2, and DCL3) and siRNA effectors AGO4, AGO6, and AGO9 have been involved in MMC formation, a recent finding show that the de novo DNA methyltransferases DRM1 and DRM2 are required for the restriction of additional MMC formation (Mendes et al., 2020), further indicating that the RdDM pathway is necessary for MMC specification and differentiation. Interestingly, SEEDSTICK (STK), a MADS-box transcription factor controlling the ovule identity, binds to the CArG-box regions of $A G O 9$ and $R D R 6$ to promote their expression, and finally promoting expression of SPL/NZZ (Mendes et al., 2020). Moreover, in contrast to that the expression of $S P L / N Z Z$ is confined to the tip of early ovule/L1 layer in the wild type plants, $S P L / N Z Z$ ectopically expands throughout the distal nucellar primordium in the ago 9 and drm1drm 2 mutants (Mendes et al., 2020). The establishment of the STK-RdDM-SPL/NZZ relay provides direct evidence how RdDM activities is integrated by both upstream and downstream transcription factors during a specific developmental process.

Although MET1, a DNA methyltransferase responsible for CG methylation in Arabidopsis (Xiao et al., 2003), is ubiquitously expressed during MMC formation (Ingouff et al., 2017; Li et al., 2017), the met1 mutant exhibits additional MMC-like cells per ovule (Li et al., 2017). Moreover, ARID1 (ARID domain-containing 1), a transcription factor that is required for heterochromatic silencing and sperm cell formation (Zheng et al., 2014), regulates MET1 reciprocally in the gamete cells, and also inhibit MMC formation (Li et al., 2017). In addition, ARID1 acts with AGO9 together to mediate siRNA movement in male gametes (Wu et al., 2021). The fact that multiple heterochromatin regulators, for example, RdDM factors, H1, MET1, and ARID1, even TRAF Mediated Gametogenesis Progression (TRAMGaP), an AGO9-interacting protein (Singh et al., 2017), negatively regulate $\mathrm{MMC}$ specification and differentiation, indicates that heterochromatin silencing restricts the potential germline identity of the surrounding somatic cells.

\section{EPIGENETIC REGULATION OF MEGASPORE MOTHER CELL FORMATION IN OTHER PLANTS}

Although most angiosperms and gymnosperms harbor only one MMC, some plant species naturally develop more than one MMC. For example, Trimenia moorei, an ancient angiosperm, exhibits multiple MMCs (Bachelier and Friedman, 2011). Gnetum, an atypical gymnosperm, forms up to 12 MMCs and 5 of them are able to even enter meiosis (Lora et al., 2019). Why these plants develop multiple MMCs? A recent finding shows that Utricularia gibba, a carnivorous plant, has an unusual distribution of small RNAs and reduced global DNA methylation levels (Cervantes-Perez et al., 2021). Intriguingly, a truncated DCL3 correlates with reduced small RNA levels and DNA methylation levels, and female gametogenesis abnormalities in U. gibba (Cervantes-Perez et al., 2021). This finding further provides evidence that small RNA activity might be a driving force for MMC specification. Moreover, U. gibba might be an ideal system to investigate the evolution relationship between the RdDM pathway and MMC numbers.

A previous study ever documented the effects of natural variation of epigenetic regulators on MMC development in different ecotype of Arabidopsis (Rodriguez-Leal et al., 2015). By comparing the frequency of multiple MMCs incidence F1 hybrids of specific ecotypes, the authors show that the transcriptional patterns and protein subcellular localization of AGO9 contribute to varied MMC development among different ecotypes to an extent (Rodriguez-Leal et al., 2015). Besides Arabidopsis, several lines of evidence further show that the core genes in the small RNA pathway and DNA methylation are possibly required for MMC development. For example, loss-of-function of $d m t 102$ and $d m t 103$, two DNA methyltransferases in maize, caused apomictic 
ovule development (Garcia-Aguilar et al., 2010). AGO104, a homolog of AGO9 in maize, is also expressed in the somatic cells surrounding the MMC, and AGO104 is required for inhibiting the transition of the germline cells to the somatic cell (Singh et al., 2011). In pineapple, many genes in the RdDM pathway are highly expressed in the MMC-stage ovule (Zhao et al., 2021). Collectively, the existence of small RNA and DNA methylation-mediated gene silencing in various plant species and the expression of the corresponding genes in the ovule primordium indicate epigenetic regulation is a widely mechanism during MMC development.

\section{CONCLUSION AND PERSPECTIVE}

Considering the importance of MMC as the first female germline cell lineage in plants, to understand how this specific cell is specialized and differentiated is especially central for plant reproductive development. Classical genetic strategies have identified that several key developmental factors promote MMC specification and differentiation, such as SPL/NZZ, KRPs, RBR1, and WUS. Individual analyses of specific epigenetic regulators and epigenetic modifications show that many genes related to small RNA biogenesis and activity, DNA methylation, heterochromatin silencing, histone variants, and histone modifications, are required for MMC formation by restricting the germline identity of the surrounding somatic cells. Future work about the nature of the very beginning trigger sensed by these key factors will provide us a blueprint of the mechanism for cell fate control in plants.

\section{REFERENCES}

Allen, E., Xie, Z., Gustafson, A. M., and Carrington, J. C. (2005). microRNAdirected phasing during trans-acting siRNA biogenesis in plants. Cell 121, 207-221. doi: 10.1016/j.cell.2005.04.004

Ascenzi, R., and Gantt, J. S. (1997). A drought-stress-inducible histone gene in Arabidopsis thaliana is a member of a distinct class of plant linker histone variants. Plant Mol. Biol. 34, 629-641. doi: 10.1023/a:1005886011722

Bachelier, J. B., and Friedman, W. E. (2011). Female gamete competition in an ancient angiosperm lineage. Proc. Natl. Acad. Sci. U.S.A. 108, 12360-12365. doi: 10.1073 /pnas. 1104697108

Balasubramanian, S., and Schneitz, K. (2000). NOZZLE regulates proximal-distal pattern formation, cell proliferation and early sporogenesis during ovule development in Arabidopsis thaliana. Development 127, 4227-4238. doi: 10. 1242/dev.127.19.4227

Bender, J. (2004). Chromatin-based silencing mechanisms. Curr .Opin. Plant Biol. 7, 521-526. doi: 10.1016/j.pbi.2004.07.003

Berr, A., McCallum, E. J., Menard, R., Meyer, D., Fuchs, J., Dong, A., et al. (2010). Arabidopsis SET DOMAIN GROUP2 is required for H3K4 trimethylation and is crucial for both sporophyte and gametophyte development. Plant Cell 22, 3232-3248. doi: 10.1105/tpc.110.079962

Borges, F., and Martienssen, R. A. (2015). The expanding world of small RNAs in plants. Nat. Rev. Mol. Cell Biol. 16, 727-741. doi: 10.1038/nrm4085

Cervantes-Perez, S. A., Yong-Villalobos, L., Florez-Zapata, N. M. V., OropezaAburto, A., Rico-Resendiz, F., Amasende-Morales, I., et al. (2021). Atypical DNA methylation, sRNA-size distribution, and female gametogenesis in Utricularia gibba. Sci. Rep. 11:15725. doi: 10.1038/s41598-021-95054-y

Chen, G. H., Sun, J. Y., Liu, M., Liu, J., and Yang, W. C. (2014). SPOROCYTELESS is a novel embryophyte-specific transcription repressor that interacts with TPL
Based on the differential patterns of DNA methylation, small RNA activities, and in the distribution of histone variants and histone modifications between the MMC and the surrounding somatic cells, an epigenetic dimorphism is established during MMC specification and differentiation. This dimorphism of epigenetic reprogramming might be such an above-mentioned possible trigger. Therefore, it would be very useful to create an accurate map of epigenetic dimorphism during MMC formation, if the technique difficulty of isolating high quality single cells from the early ovule primordium can be overcome in the future.

\section{AUTHOR CONTRIBUTIONS}

All authors listed have made a substantial, direct, and intellectual contribution to the work, and approved it for publication.

\section{FUNDING}

This work was supported by the National Natural Science Foundation of China (32025005, 31830045, and M-0398) and the Ministry of Science and Technology of China (2021YFC2600100).

\section{ACKNOWLEDGMENTS}

We apologize for not able to refer to some related literatures due to page limit.

and TCP proteins in Arabidopsis. J. Genet. Genom. 41, 617-625. doi: 10.1016/j. jgg.2014.08.009

Ebel, C., Mariconti, L., and Gruissem, W. (2004). Plant retinoblastoma homologues control nuclear proliferation in the female gametophyte. Nature 429, 776-780. doi: $10.1038 /$ nature 02637

Garcia-Aguilar, M., Michaud, C., Leblanc, O., and Grimanelli, D. (2010). Inactivation of a DNA methylation pathway in maize reproductive organs results in apomixis-like phenotypes. Plant Cell 22, 3249-3267. doi: 10.1105/tpc. 109.072181

Grossniklaus, U., and Schneitz, K. (1998). The molecular and genetic basis of ovule and megagametophyte development. Semin. Cell Dev. Biol. 9, 227-238. doi: 10.1006/scdb.1997.0214

Guo, L., Yu, Y., Law, J. A., and Zhang, X. (2010). SET DOMAIN GROUP2 is the major histone H3 lysine 4 trimethyltransferase in Arabidopsis. Proc. Natl. Acad. Sci. U.S.A. 107, 18557-18562. doi: 10.1073/pnas.1010478107

He, S., Vickers, M., Zhang, J., and Feng, X. (2019). Natural depletion of histone H1 in sex cells causes DNA demethylation, heterochromatin decondensation and transposon activation. Elife 8:42530. doi: 10.7554/eLife.42530

Hernandez-Lagana, E., and Autran, D. (2020). H3.1 eviction marks female germline precursors in Arabidopsis. Plants 9:322. doi: 10.3390/plants9101322

Hernandez-Lagana, E., Mosca, G., Mendocilla-Sato, E., Pires, N., Frey, A., GiraldoFonseca, A., et al. (2021). Organ geometry channels reproductive cell fate in the Arabidopsis ovule primordium. Elife 10:66031. doi: 10.7554/eLife.66031

Hernandez-Lagana, E., Rodriguez-Leal, D., Lua, J., and Vielle-Calzada, J. P. (2016). A multigenic network of ARGONAUTE4 clade members controls early megaspore formation in Arabidopsis. Genetics 204, 1045-1056. doi: 10.1534/ genetics.116.188151

Ingouff, M., Rademacher, S., Holec, S., Soljic, L., Xin, N., Readshaw, A., et al. (2010). Zygotic resetting of the HISTONE 3 variant repertoire participates in epigenetic 
reprogramming in Arabidopsis. Curr. Biol. 20, 2137-2143. doi: 10.1016/j.cub. 2010.11.012

Ingouff, M., Selles, B., Michaud, C., Vu, T. M., Berger, F., Schorn, A. J., et al. (2017). Live-cell analysis of DNA methylation during sexual reproduction in Arabidopsis reveals context and sex-specific dynamics controlled by noncanonical RdDM. Genes Dev. 31, 72-83. doi: 10.1101/gad.289397.116

Jacob, Y., Bergamin, E., Donoghue, M. T., Mongeon, V., LeBlanc, C., Voigt, P., et al. (2014). Selective methylation of histone $\mathrm{H} 3$ variant $\mathrm{H} 3.1$ regulates heterochromatin replication. Science 343, 1249-1253. doi: 10.1126/science. 1248357

Jauvion, V., Elmayan, T., and Vaucheret, H. (2010). The conserved RNA trafficking proteins HPR1 and TEX1 are involved in the production of endogenous and exogenous small interfering RNA in Arabidopsis. Plant Cell 22, 2697-2709. doi: $10.1105 /$ tpc.110.076638

Li, L., Wu, W., Zhao, Y., and Zheng, B. (2017). A reciprocal inhibition between ARID1 and MET1 in male and female gametes in Arabidopsis. J. Integr. Plant Biol. 59, 657-668. doi: 10.1111/jipb.12573

Lieber, D., Lora, J., Schrempp, S., Lenhard, M., and Laux, T. (2011). Arabidopsis WIH1 and WIH2 genes act in the transition from somatic to reproductive cell fate. Curr. Biol. 21, 1009-1017. doi: 10.1016/j.cub.2011.05.015

Lora, J., Yang, X., and Tucker, M. R. (2019). Establishing a framework for female germline initiation in the plant ovule. J. Exp. Bot. 70, 2937-2949. doi: 10.1093/ jxb/erz212

Matzke, M. A., and Mosher, R. A. (2014). RNA-directed DNA methylation: an epigenetic pathway of increasing complexity. Nat. Rev. Genet. 15, 394-408. doi: $10.1038 / \operatorname{nrg} 3683$

Mendes, M. A., Petrella, R., Cucinotta, M., Vignati, E., Gatti, S., Pinto, S. C., et al. (2020). The RNA-dependent DNA methylation pathway is required to restrict SPOROCYTELESS/NOZZLE expression to specify a single female germ cell precursor in Arabidopsis. Development 147:194274. doi: 10.1242/dev.194274

Okada, T., Endo, M., Singh, M. B., and Bhalla, P. L. (2005). Analysis of the histone $\mathrm{H} 3$ gene family in Arabidopsis and identification of the male-gamete-specific variant AtMGH3. Plant J. 44, 557-568. doi: 10.1111/j.1365-313X.2005.02554.x

Olmedo-Monfil, V., Duran-Figueroa, N., Arteaga-Vazquez, M., Demesa-Arevalo, E., Autran, D., Grimanelli, D., et al. (2010). Control of female gamete formation by a small RNA pathway in Arabidopsis. Nature 464, 628-632. doi: 10.1038/ nature 08828

Osipova, T. N., Pospelov, V. A., Svetlikova, S. B., and Vorob'ev, V. I. (1980). The role of histone $\mathrm{H} 1$ in compaction of nucleosomes. sedimentation behaviour of oligonucleosomes in solution. Eur. J. Biochem. 113, 183-188. doi: 10.1111/ j.1432-1033.1980.tb06153.x

Otero, S., Desvoyes, B., Peiro, R., and Gutierrez, C. (2016). Histone H3 dynamics reveal domains with distinct proliferation potential in the Arabidopsis root. Plant Cell 28, 1361-1371. doi: 10.1105/tpc.15.01003

Payne, T., Johnson, S. D., and Koltunow, A. M. (2004). KNUCKLES (KNU) encodes a $\mathrm{C} 2 \mathrm{H} 2$ zinc-finger protein that regulates development of basal pattern elements of the Arabidopsis gynoecium. Development 131, 3737-3749. doi: 10. 1242/dev.01216

Qin, Y., Zhao, L., Skaggs, M. I., Andreuzza, S., Tsukamoto, T., Panoli, A., et al. (2014). ACTIN-RELATED PROTEIN6 regulates female meiosis by modulating meiotic gene expression in Arabidopsis. Plant Cell 26, 1612-1628. doi: 10.1105/ tpc.113.120576

Ravi, M., Shibata, F., Ramahi, J. S., Nagaki, K., Chen, C., Murata, M., et al. (2011). Meiosis-specific loading of the centromere-specific histone CENH3 in Arabidopsis thaliana. PLoS Genet 7:e1002121. doi: 10.1371/journal.pgen. 1002121

Ren, L., Tang, D., Zhao, T., Zhang, F., Liu, C., Xue, Z., et al. (2018). OsSPL regulates meiotic fate acquisition in rice. New Phytol. 218, 789-803. doi: 10.1111/nph. 15017

Rodriguez-Leal, D., Leon-Martinez, G., Abad-Vivero, U., and Vielle-Calzada, J. P. (2015). Natural variation in epigenetic pathways affects the specification of female gamete precursors in Arabidopsis. Plant Cell 27, 1034-1045. doi: 10. $1105 /$ tpc. 114.133009

Rogers, K., and Chen, X. (2013). Biogenesis, turnover, and mode of action of plant microRNAs. Plant Cell 25, 2383-2399. doi: 10.1105/tpc.113.113159

Rojas-Gracia, P., Roque, E., Medina, M., Rochina, M., Hamza, R., Angarita-Diaz, M. P., et al. (2017). The parthenocarpic hydra mutant reveals a new function for a SPOROCYTELESS-like gene in the control of fruit set in tomato. New Phytol. 214, 1198-1212. doi: 10.1111/nph.14433

Schiefthaler, U., Balasubramanian, S., Sieber, P., Chevalier, D., Wisman, E., and Schneitz, K. (1999). Molecular analysis of NOZZLE, a gene involved in pattern formation and early sporogenesis during sex organ development in Arabidopsis thaliana. Proc. Natl. Acad. Sci. U.S.A. 96, 11664-11669. doi: 10.1073/pnas.96.20. 11664

Schneitz, K., Hulskamp, M., Kopczak, S. D., and Pruitt, R. E. (1997). Dissection of sexual organ ontogenesis: a genetic analysis of ovule development in Arabidopsis thaliana. Development 124, 1367-1376. doi: 10.1242/dev.124.7.1367

She, W., Grimanelli, D., Rutowicz, K., Whitehead, M. W., Puzio, M., Kotlinski, M., et al. (2013). Chromatin reprogramming during the somatic-to-reproductive cell fate transition in plants. Development 140, 4008-4019. doi: 10.1242/dev. 095034

Singh, M., Goel, S., Meeley, R. B., Dantec, C., Parrinello, H., Michaud, C., et al. (2011). Production of viable gametes without meiosis in maize deficient for an ARGONAUTE protein. Plant Cell 23, 443-458. doi: 10.1105/tpc.110.079020

Singh, S. K., Kumar, V., Srinivasan, R., Ahuja, P. S., Bhat, S. R., and Sreenivasulu, Y. (2017). The TRAF mediated gametogenesis progression (TRAMGaP) gene is required for megaspore mother cell specification and gametophyte development. Plant Physiol. 175, 1220-1237. doi: 10.1104/pp.17.00275

Su, Z., Wang, N., Hou, Z., Li, B., Li, D., Liu, Y., et al. (2020). Regulation of female germline specification via small RNA mobility in Arabidopsis. Plant Cell 32, 2842-2854. doi: 10.1105/tpc.20.00126

Su, Z., Zhao, L., Zhao, Y., Li, S., Won, S., Cai, H., et al. (2017). The THO complex non-cell-autonomously represses female germline specification through the TAS3-ARF3 module. Curr Biol 27, 1597-1609.e1592. doi: 10.1016/j.cub.2017. 05.021

Talbert, P. B., Masuelli, R., Tyagi, A. P., Comai, L., and Henikoff, S. (2002). Centromeric localization and adaptive evolution of an Arabidopsis histone H3 variant. Plant Cell 14, 1053-1066. doi: 10.1105/tpc.010425

van Zanten, M., Koini, M. A., Geyer, R., Liu, Y., Brambilla, V., Bartels, D., et al. (2011). Seed maturation in Arabidopsis thaliana is characterized by nuclear size reduction and increased chromatin condensation. Proc. Natl. Acad. Sci. U.S.A. 108, 20219-20224. doi: 10.1073/pnas. 1117726108

Wang, H., Dittmer, T. A., and Richards, E. J. (2013). Arabidopsis CROWDED NUCLEI (CRWN) proteins are required for nuclear size control and heterochromatin organization. BMC Plant Biol. 13:200. doi: 10.1186/14712229-13-200

Wei, B., Zhang, J., Pang, C., Yu, H., Guo, D., Jiang, H., et al. (2015). The molecular mechanism of sporocyteless/nozzle in controlling Arabidopsis ovule development. Cell Res. 25, 121-134. doi: 10.1038/cr.2014.145

Wu, W., Li, L., Zhao, Y., Zhao, Y., Jiang, T., McCormick, S., et al. (2021). Heterochromatic silencing is reinforced by ARID1-mediated small RNA movement in Arabidopsis pollen. New Phytol. 229, 3269-3280. doi: 10.1111/ nph.16871

Xiao, W., Gehring, M., Choi, Y., Margossian, L., Pu, H., Harada, J. J., et al. (2003). Imprinting of the MEA polycomb gene is controlled by antagonism between MET1 methyltransferase and DME glycosylase. Dev. Cell 5, 891-901. doi: 10.1016/s1534-5807(03)00361-7

Yang, W. C., Ye, D., Xu, J., and Sundaresan, V. (1999). The SPOROCYTELESS gene of Arabidopsis is required for initiation of sporogenesis and encodes a novel nuclear protein. Genes Dev. 13, 2108-2117. doi: 10.1101/gad.13.16.2108

Yao, X., Yang, H., Zhu, Y., Xue, J., Wang, T., Song, T., et al. (2018). The canonical E2Fs are required for germline development in Arabidopsis. Front. Plant Sci. 9:638. doi: 10.3389/fpls.2018.00638

Yelina, N. E., Smith, L. M., Jones, A. M., Patel, K., Kelly, K. A., and Baulcombe, D. C. (2010). Putative Arabidopsis THO/TREX mRNA export complex is involved in transgene and endogenous siRNA biosynthesis. Proc. Natl. Acad. Sci. U.S.A. 107, 13948-13953. doi: 10.1073/pnas.0911341107

Zemach, A., Kim, M. Y., Hsieh, P. H., Coleman-Derr, D., Eshed-Williams, L., Thao, K., et al. (2013). The Arabidopsis nucleosome remodeler DDM1 allows DNA methyltransferases to access H1-containing heterochromatin. Cell 153, 193-205. doi: 10.1016/j.cell.2013.02.033

Zhao, H., Guo, M., Yan, M., Cheng, H., Liu, Y., She, Z., et al. (2020). Comparative expression profiling reveals genes involved in megasporogenesis. Plant Physiol. 182, 2006-2024. doi: 10.1104/pp.19.01254 
Zhao, L., Cai, H., Su, Z., Wang, L., Huang, X., Zhang, M., et al. (2018). KLU suppresses megasporocyte cell fate through SWR1-mediated activation of WRKY28 expression in Arabidopsis. Proc. Natl. Acad. Sci. U.S.A. 115, E526E535. doi: 10.1073/pnas.1716054115

Zhao, L., Liu, L., Liu, Y., Dou, X., Cai, H., Aslam, M., et al. (2021). Characterization of germline development and identification of genes associated with germline specification in pineapple. Hortic Res. 8:239. doi: 10.1038/s41438-021-00 669-x

Zhao, X., Bramsiepe, J., Van Durme, M., Komaki, S., Prusicki, M. A., Maruyama, D., et al. (2017). RETINOBLASTOMA RELATED1 mediates germline entry in Arabidopsis. Science 356:aaf6532. doi: 10.1126/science.aaf 6532

Zheng, B., He, H., Zheng, Y., Wu, W., and McCormick, S. (2014). An ARID domain-containing protein within nuclear bodies is required for sperm cell formation in Arabidopsis thaliana. PLoS Genet 10:e1004421. doi: 10.1371/ journal.pgen.1004421
Conflict of Interest: The authors declare that the research was conducted in the absence of any commercial or financial relationships that could be construed as a potential conflict of interest.

Publisher's Note: All claims expressed in this article are solely those of the authors and do not necessarily represent those of their affiliated organizations, or those of the publisher, the editors and the reviewers. Any product that may be evaluated in this article, or claim that may be made by its manufacturer, is not guaranteed or endorsed by the publisher.

Copyright (c) 2022 Jiang and Zheng. This is an open-access article distributed under the terms of the Creative Commons Attribution License (CC BY). The use, distribution or reproduction in other forums is permitted, provided the original author(s) and the copyright owner(s) are credited and that the original publication in this journal is cited, in accordance with accepted academic practice. No use, distribution or reproduction is permitted which does not comply with these terms. 